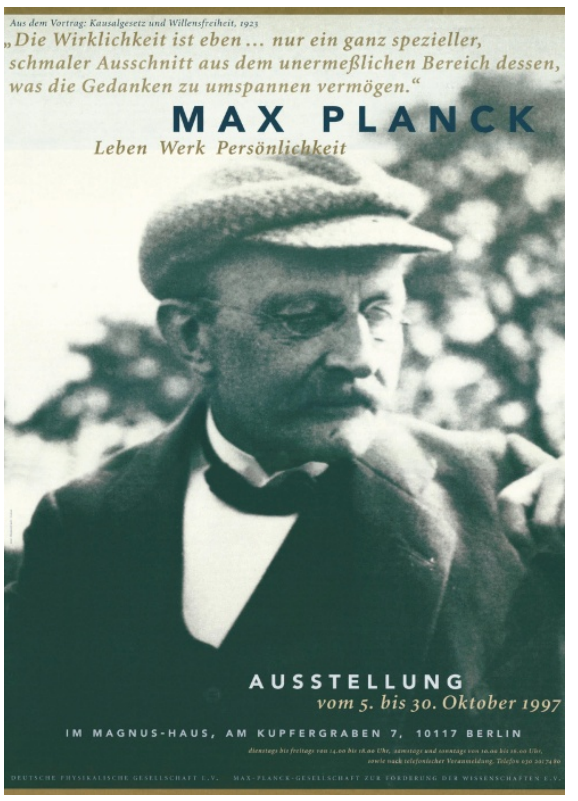

\section{German physicists honour Planck}

[MUNICH] The fiftieth anniversary of the death of the German physicist Max Planck on 4 October 1947 is to be marked by the Max Planck Society and the German Physical Society with an extensive exhibition describing his life and work.

The exhibition in Magnus House, Berlin, runs from 5 to 30 October. It includes personal items such as Planck's rucksack and icepick - he was a keen mountain hiker and documents that have not been publicly exhibited before. It will also be the first public showing for his death mask.

More familiar items to be exhibited include the minute books of the German Physical Society which record, for example, the lecture Planck gave to the society in Berlin in 1900 in which he described his law of radiation and introduced for the first time his quantum hypothesis.

Also familiar to Planck aficionados is the 20-minute film commissioned by Joseph Goebbels' ministry of propaganda in 1942, discovered in 1983. The film, which will run continuously throughout the exhibition, features Planck, sitting on a stool, discussing his life. The film was not actually used for propaganda - it was one of a series intended to archive the lives of great Germans.

Magnus House, in former East Berlin, has strong associations with recent German history. The family of Gustav Magnus, the German physicist who in the last century discovered the Magnus effect (the sideways force exerted on a rotating body moving through a fluid), donated the house to the German Physical Society of the former German Democratic Republic in 1958, in honour of the centenary of Planck's birth. After reunification, the house was transferred to the unified German Physical Society. Alison Abbott

\title{
NASA to fund life science beam line at Brookhaven?
}

[WASHINGTON] A facility proposed for the Brookhaven National Laboratory in New York state would give space biologists more opportunity to study the effects of cosmic radiation on living organisms — research that is critical if future astronauts are to travel to the Moon and Mars.

The proposed Booster Applications Facility (BAF) could begin construction next year and would probably be funded primarily by the US National Aeronautics and Space Administration (NASA). The White House's science and budget offices have yet to decide how NASA and the Department of Energy, which runs Brookhaven, would split the construction costs for the BAF (about \$20 million), and the $\$ 4$ million a year operating costs. Funding would have to be approved by Congress as part of the 1999 budget request.

Richard Setlow, Brookhaven's associate director for life sciences, says that life scientists in NASA have long sought such a facility, as heavy, fast-moving atomic particles pose perhaps the greatest potential health threat to humans venturing beyond Earth orbit.

Astronauts in Earth orbit are protected from galactic cosmic radiation by the Earth's magnetic field. But interplanetary voyagers run the risk of cancer, damage to the nervous system and other problems from bombardment by iron nuclei and other heavy particles.

Little is known about the biological effects of these high-energy particles, says Setlow. The research is hard to do in space because of the difficulty of working with large numbers of test animals and the relative scarcity of radiation in space — the dosages would build up only after many months of exposure. NASA researchers scrounge about two weeks a year on accelerators at Brookhaven and elsewhere. But that is not enough, Setlow says.

Setlow chaired a National Research Council study last year that called on NASA to boost a programme of ground-based research in this area if it expects to be ready to send humans to Mars in 20 years. But expanded use of existing ground-based facilities would interfere with higher priority physics experiments.

The BAF would divert a new beam line from a circular 'booster' accelerator that shoots pulses of heavyions into Brookhaven's Alternating Gradient Synchrotron (AGS), which is used by high-energy physicists. Because the AGS receives particles in bursts rather than continuously, the bursts could alternate rapidly between beams without disrupting physics experiments, says Setlow.

Biologists would expose cell cultures and laboratory animals to the radiation. Other scientists would study how different materials perform as radiation shields. NASA may also be interested in the effects of heavy ions on microcircuitry, says Setlow. He expects users for the BAF to number in the hundreds.

There is some urgency to begin construction soon, he says. Diverting a new beam requires breaking into the booster tunnel and installing new steering magnets. This would have to be done before physicists begin using the Relativistic Heavy Ion Collider (RHIC), a major Brookhaven facility due to go on-line in 1999. The collider is fed by the same booster. As a first step, NASA will pay for an environmental impact study of the proposed new facility.

Tony Reichhardt

\section{France asked to drop $\mathbf{N}$-test simulations}

[PARIS] Four unions representing French researchers have written a joint letter to Alain Richard, the minister of defence, asking the government to drop its plans for a programme of computer simulations of nuclear weapons explosions, called PALEN.

The unions - the SNCS, the SNTRSCGT, the SNES-FSU and the SNPCEN-FSU - whose members include both university teachers and nuclear physicists, point out that during his election campaign Prime Minister Lionel Jospin wrote that it was "pointless to launch a programme of test simulations that would be costly and unproductive, and could threaten to provoke a reopening of the arms race".

The scientists have sent copies of the letter to President Jacques Chirac, Claude Allègre, the minister of national education, and Jospin himself.

"We are not seeking unilateral disarmament, merely that France commits to the path opened by the non-proliferation treaty," says Marc Ollivier, the coordinator of the initiative. He points to an interpretation of article 6 of the treaty by the International Court of Justice, stating that "an obligation exists to pursue in good faith up to their conclusion all aspects of negotiations leading to nuclear disarmament".

The unions claim that the PALEN programme does not comply with this commitment, and the researchers ask for the setting up of a broad interdisciplinary programme, involving those engaged in both the natural and the social sciences and associated with the Ministry of Defence, to prepare for disarmament.

Eric Glover 